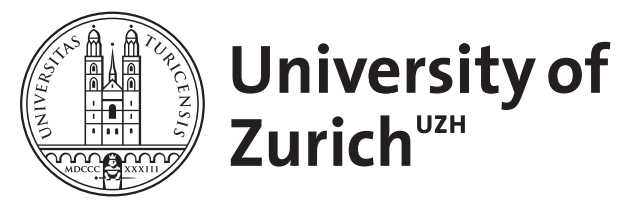

\title{
What does it take to be a true conservative?
}

Beckstein, Martin

\begin{abstract}
Is there any reason to discriminate among the rival claims self-proclaimed conservatives make for being truly conservative? This article argues that at least some of these claims can legitimately be dismissed by an independent third. Drawing on and critically interrogating the theories of conservatism provided by Huntington, Oakeshott, as well as Brennan and Hamlin, this article argues that many characterizations of conservatism mistake contingent circumstances explaining why people historically were or conceivably might be reluctant to promote social change for a fully-formed conservative ideology. Not least, risk- and uncertainty-centred accounts, which have gained in popularity as of recently, constitute no viable basis for plausible claims to being truly conservative. Rather than specifying what it takes to be a true conservative, these accounts provide a formalized description of one kind of contingent circumstances that may lead a principled non-conservative to adopt conservative political attitudes.
\end{abstract}

DOI: https://doi.org/10.1080/23269995.2014.933566

Posted at the Zurich Open Repository and Archive, University of Zurich

ZORA URL: https://doi.org/10.5167/uzh-96912

Journal Article

Accepted Version

Originally published at:

Beckstein, Martin (2015). What does it take to be a true conservative? Global Discourse, 5(1):4-21.

DOI: https://doi.org/10.1080/23269995.2014.933566 


\section{WHAT DOES IT TAKE TO BE A TRUE CONSERVATIVE?}

Martin Beckstein, University of Zurich

This is an Accepted Manuscript of an article published in Global Discourse on 27 June 2014, available online:

http://www.tandfonline.com/http://www.tandfonline.com/doi/abs/10.1080/23269995.2014.933566\#t abModule (DOI: 10.1080/23269995.2014.933566)

\section{ABSTRACT}

Is there any reason to discriminate among the rival claims self-proclaimed conservatives make for being truly conservative? This article argues that at least some of these claims can legitimately be dismissed by an independent third. Drawing on and critically interrogating the theories of conservatism provided by Huntington, Oakeshott, as well as Brennan and Hamlin, this article argues that many characterizations of conservatism mistake contingent circumstances explaining why people historically were or conceivably might be reluctant to promote social change for a fully-formed conservative ideology. Not least, risk- and uncertainty-centred accounts, which have gained in popularity as of recently, constitute no viable basis for plausible claims to being truly conservative. Rather than specifying what it takes to be a true conservative, these accounts provide a formalized description of one kind of contingent circumstances that may lead a principled non-conservative to adopt conservative political attitudes.

\section{KEYWORDS}

Authenticity, Conservatism, Ideology, Scepticism, Social Disputes

\section{CONTACT DETAILS}

Dr Martin Beckstein

University of Zurich, Institute of Philosophy

Zollikerstrasse 117, CH-8008 Zurich, Switzerland

Phone: +41446348534

Fax +41446348509

E-mail: martin.beckstein@philos.uzh.ch 


\section{INTRODUCTION}

Every once in a while questions arise as to whether some leader of a conservative party is really faithful to conservatism: Is David Cameron an authentic conservative? Was Margaret Thatcher? Leaders of conservative parties, if confronted with such doubts, usually rush to assert their truly conservative credentials - just as Cameron has done more than once - while fellow party members, journalists, and other commentators weigh in on both sides of the dispute. There is something at stake in such disputes, or so it seems. Yet what does it take to be a true conservative? Can the question be answered plausibly in more than one way? And on what grounds, if any, can we dismiss at least some claims to being truly conservative?

Disputes over authenticity are not specific to conservative parties, nor even to political organizations. They may arise within any group of persons that requires a commitment to some set of beliefs or practices from its members, including, for instance, religious communities and academic schools of thought. Yet disputes over authenticity among self-proclaimed conservatives constitute a particularly interesting case. They promise to be neither irrelevant for social life, as merely academic disputes might seem to be, nor to foreclose rational solutions, as disputes in religious contexts tend to do; at the same time they appear to be much more difficult to handle than disputes over authenticity among self-proclaimed adherents to other political ideologies because conservatism is somewhat different. Liberals and socialists, it is often said, respectively share roughly the same abstract ideal of the good society in spite of disagreeing on how that ideal can be realized. At least, they can be expected to push in a common direction. Conservatives, in contrast, commonly affirm that they do not approximate a utopia, and are notorious for holding back all those who push. Being conservative, it is often said, requires a specific posture rather than a specific programme. Yet is this posture a stance towards time-honoured traditions, the present status quo, innovation, or change more generally? It is not even clear whether much sense can be made of such a posture in politics at all.

This article attempts to add clarity, on a theoretical level, to disputes over authenticity among self-proclaimed conservatives. One task is therefore to identify, compare, and evaluate different frameworks and accounts for analyzing conservatism. However, as disputes over authenticity concern the identification of persons with 
something rather than the identity of the thing alone, the guiding question is not what conservatism is, but rather what the characterization of somebody as truly conservative implies. It needs therefore to be considered whether the conceptions that are revealed by different frameworks and accounts for the analysis of conservatism are equally suited to specify what being conservative requires of a person, and if it makes a difference, what it means to be truly conservative.

The first section introduces the subject of disputes over authenticity, focusing particularly on such disputes in political contexts. The argument developed in the rest of the article then unfolds in the following dialectic: section two proceeds with Huntington's characterization of conservatism as a situational ideology that is wellsuited for capturing the peculiarity of conservatism. Section three relies on Brennan and Hamlin's recent writings to solve the ambiguity in Huntington's account in regard to whether the conservative posture is rather a (scepticist, "adjectival") disposition to oppose change or a (substantive, "nominal") inclination to stick with the status quo, and establishes that both inclinations articulate plausible, and analytically distinct, conceptions of conservatism. The fourth section takes the distinction between conservative convictions and conservative conduct that is implicit in Oakeshott's On Being Conservative as a basis for questioning whether the adjectival and the nominal conceptions of conservatism can serve as equally plausible bases for being truly conservative. It is revealed that there is indeed more than one correct answer to what it takes to be a true conservative. However, the varieties of being truly conservative owe their existence primarily to the vagueness of the concept of the status quo, while all of them require a nominal conservative esteem for the status quo simply because it is the status quo. References to the adjectival inclination, which originates from risk and uncertainty-related reservations about change, in contrast, do not justify claims to ideological authenticity in disputes among self-proclaimed conservatives. This claim is corroborated by the consideration of a hypothetical reversal test in the fourth section, and the refutation of a scepticist objection in the fifth section.

Beyond political disputes about being truly conservative, the result of the inquiry implies that much scholarship on conservatism does not make a case for (or against) conservative convictions, but only - as explicitly recommended by Huntington and Oakeshott in the 1950s - for (or against) behaving in politics as if one were a true conservative. 


\section{DISPUTES OVER AUTHENTICITY}

Disputes over authenticity arise when two or more individuals or groups each claim that they, but not their rivals, are the genuine bearer of some quality or property. Bearing this quality or property is a matter of identity, it is (co-)constitutive of what an individual or group really is and how it is expected or entitled to think and act. In disputes over authenticity, a self-proclaimed $X$ accordingly alleges another individual or group to lack the quality or property in question, contending either that the individual or group pretends to be $X$ while actually being $Y$, or that the individual or group fails to be $X$ without being aware of it. Numerous examples of such disputes come readily to mind, for instance conflicts between Shia and Sunni over the meaning of Islam or Catholics and Protestants over what it means to be Christian, between Stalinists and Trotskyists over the faithful succession of Leninism, or between Left and Right Hegelians. ${ }^{1}$

Although disputes over authenticity manifest themselves as struggles over labels, they are not fought for the sake of mere labelling. Multiplying the meaning of a term (e.g. Islam 1, Islam 2) will rarely settle the affair. At stake is not primarily the name, by which contenders are labelled, but rather the authority-conferring title that comes along with it - in other words, the credit of trust with which sympathizers with a particular quality or property endow bearers of that quality or property. In the view of critics, of course, holding such a title has the opposite effect, which is why claims in disputes over authenticity occasionally take a negative form where disputants deny bearing the quality or property in question. Prominent examples in the case of conservatism include Hayek's (2011) apology Why I Am Not a Conservative as well as Buchanan's (2005) article Why I, Too, Am Not a Conservative.

Solving disputes over authenticity in a rational manner is sometimes a matter of fact, for instance if the criteria of authenticity are regulated by generally acknowledged orders of succession. Whether a female member of a dynasty has a rightful claim to the throne in a hereditary monarchy with male-preference cognatic primogeniture depends on whether she has living brothers or deceased brothers with male descendants. The problems that may occur when deciding the issue are practical in nature, as they were,

1 For a seminal analysis of certain forms of disputes over authenticity, namely true succession and rightful inheritance of a tradition, see Ruben (2013, esp. 32-34). 
for instance, when doubts arouse as to whether James Francis Edward Stuart ("The Old Pretender") was a biological child of James II of England just like (Queen) Anne. However, often the disputes are more intricate because the criteria of authenticity are neither formally regulated nor informally agreed upon by the disputants, and anyway revolve around softer qualities than biological kinship. Claims to authenticity will then have to be assessed on the basis of content-related criteria of the disputed identity: the beliefs or practices of a person are decisive for her being a genuine bearer of the quality in question or not. A person is an authentic Christian, Muslim, Leninist, or Hegelian if her beliefs or practices match, in the relevant regard, with Christian, Islamic, Leninist, or Hegelian doctrine. In such cases, the verification of a disputant's claim to authenticity is a challenging task because theoretical problems arise in addition to practical ones.

A straightforward theoretical problem for solving disputes over authenticity in which the claims concern matching beliefs or practices is that disputants may occasionally justify their claims with apodictic methods of verification. Some rival in a dispute about the correct meaning of being a faithful Christian might feel justified to reject all scholarly exegetic interpretations of the Bible because she believes to have a privileged access to the truth. The belief of one or more rivals in divine afflatus wrecks all hope for solving disputes over authenticity in a rational way. The Papal Infallibility arguably constitutes, from the perspective of an independent third, such a conversation stopper. At best, the disputants could agree to tolerate or ignore each other's claims; at worst, one disputant tries to impose her view upon her rivals by the use of sheer force. In scholarly discourse, this theoretical problem should usually not arise. Nevertheless there is still considerable room for disagreement in disputes over authenticity. Disputant $X$ might for instance presuppose that the meaning of Wittgenstein's (and any self-proclaimed faithful successor's) thought is to be determined by an analysis of the propositional content of his writings; $Y$ might instead request an exegesis of authorial intention, and $Z$ think that a contextual approach is needed. Moreover, the disputants could disagree about which writings need to be considered (e.g. may Wittgenstein's "secret diaries" be ignored?) and beliefs be shared (e.g. Wittgenstein's disrespect for modern music), or whether actions are a relevant factor, too (e.g. Wittgenstein's volunteering for the army). Not least, rivals in scholarly disputes will have different answers about whether and how the predecessor's beliefs or practices must be adapted to the successors' times. Finally, they could disagree about which sociological, technological, economic, and other changes have occurred in the meantime that necessitate a re-contextualization (in order to make 
sure that the successor's doctrine is in her world what the original doctrine was in its world), and how or whether the original doctrine can be extended and developed further without adulteration. In short, the theoretical obstacles for establishing accepted criteria for the evaluation of claims are manifold in non-religious disputes too.

The study of disputes over authenticity between political groups and intra-party wings in modern democracies faces comparatively favourable conditions. Disputes do not revolve around sacred scriptures or the life and letters of some hagiographic authority. Even if there are historical figures that have produced seminal texts, neither particular authors nor particular writings are pivotal for the assessment of claims. Disputes over authenticity between political groups and intra-party wings in modern democracies are disputes over ideological authenticity, not faithful succession: the decisive point of reference is a doctrine, worldview, philosophy, or the like. ${ }^{2}$ To make the point clear, scholarly disputes over authenticity may revolve around two different kinds of objects: on the one hand, they may take a systematic form and concern a doctrine, worldview, philosophy, etc.; on the other hand, they may take an exegetic form and concern an author's thought or a text's meaning. Political disputes over ideological authenticity, however, necessarily have a systematic focus. Rivals in a dispute about who is truly liberal may make reference to Mill for the sake of transparency or to indicate who first enunciated important features of liberalism. Yet as soon as Mill's thinking, with its strengths and idiosyncrasies, takes precedence over liberal ideology, the object of the dispute changes from true liberalism to the faithful succession of Mill (i.e. true Millianism). Marxism is no exception, given that Marx's writings occasionally include thoughts that articulate liberal and other "non-Marxist" views. The misleading intuition to the contrary is owed to the fact that the word "Marxism" has become the label for both Marx's thought and a political ideology. Conservatism is no exception in this regard either.

Besides ideological authenticity and faithful succession, rightful inheritance of a tradition can be distinguished as another subcategory of disputes over authenticity. Whereas faithful succession requires that a person has developed a set of beliefs or practices that is qualitatively similar, to a very high degree, to some earlier set of beliefs or practices, rightful inheritance of a tradition is defined through a causal-similarity chain. The set of beliefs or practices of a rightful inheritor of a tradition must therefore be qualitatively similar, to a very high degree, to the last link in the chain of a tradition, and so may be in fact qualitatively dissimilar to the set of beliefs or practices developed by the originator of the tradition, provided that the tradition chain includes a sufficiently high number of links in between. For a more detailed and accurate comparison see Payton $(2013,41-3)$ and Beckstein $(2014,31)$. 
However, among political ideologies conservatism is a case apart. At least, basically every discussion of conservatism includes a reflection on the "elusiveness" of this ideology. I will skip this convention and instead turn immediately to attempts to grasp the peculiarity of conservatism. ${ }^{3}$ To keep this discussion within reasonable limits, a few methodical decisions have been made which ought to be made transparent from the outset. Ideologies can be studied in a more analytic, systematic, and deductive way or in a more historical, exegetic, and inductive way. Both ways have their strengths and weaknesses. The former makes the scholar certainly vulnerable to drawing purist pictures that fail to account for the impure nature of ideologies as devices that build reciprocal links between political theory and political practice rather than being political theory plain and simple (Freeden 2008, 37). A danger for scholars relying on historical approaches to the study of ideology, however, is that they might confuse contingent implications drawn from an abstract theory with the abstract theory itself. ${ }^{4}$ What follows uses an analytic approach, firstly because it has been taken comparatively rarely (some scholars of conservatism even deny the possibility of studying conservative ideology profitably with analytic means ${ }^{5}$ ) and secondly because the dangers associated with historical approaches, to anticipate, are hard to avoid in the case of conservatism. In addition to that, I aim for a minimalist definition of conservatism rather than a comprehensive one. Ideologies are complex systems of ideas, interrelated concepts, and precepts for action, each aspect of which can be conceptualized differently and be given a different weight. Moreover, ideologies mutually overlap in many regards (Freeden 2008,40 ). Sorting out the precise borders among various ideologies is a formidable challenge to which only much more ambitious projects than this can hope to rise. ${ }^{6} \mathrm{My}$ intention in the following is therefore only to identify the distinctive, if ambiguous, principles, axioms, imperatives, presumptions, or maxims that may plausibly be invoked to account for the peculiarity of conservatism. (In the case of liberalism this might for instance be individual autonomy, and relatedly, the wish to guarantee each person the most extensive scheme of basic rights and liberties that is compatible with the same scheme of rights and liberties for everyone else.) I thus assume that the question of what

3 One aspect of this convention, as I understand it following Muller $(1997,4-5)$ and Huntington (1957, 460 ), is that (metaphysical) ideologies that postulate the existence of some transcendent order ("orthodoxy") are excluded from the spectrum of potentially plausible conceptions of conservatism, as are (reactionary) doctrines that wish to re-activate some idealized bygone state of affairs.

4 A general description of this danger is Dewey's (2007) "historical fallacy".

5 E.g. O'Hear $(1998,609)$ and White $(1957,1)$. For rejections of this view see e.g. Brennan and Hamlin (2004, 677), and Oakeshott (1991b, 407).

6 Freeden's (2008) Ideologies and Political Theory stands out as a particularly felicitous such project. 
it takes to be a true conservative can be profitably answered by analysing the logical possibilities of conceptualizing the characteristic feature of conservatism and considering whether there are two or more equally plausible characteristic features that could serve as the basis for different versions of conservatism.

\section{CONSERVATISM AS A SITUATIONAL IDEOLOGY}

A good starting point for grasping the peculiarity of the conservative ideology consists in recalling the conservative denial of ideology. Just as socialists have occasionally claimed the superiority of their doctrine vis-à-vis others in terms of scientificity, and liberals in terms of moral neutrality, so have conservatives affirmed that their doctrine does not qualify as an ideology (E.g. Kirk 1954, 22, 38-9; Minogue 1985; Oakeshott 1991a, 48; Viereck 2009, 154. Cf. also Eccleshall 2003, 50). The trick in all these cases is of course accomplished by the adoption of a definition of ideology that does not fit one's preferred doctrine and elevates it to the meta-level of political discourse. In the case of conservatism, the denial of ideology is facilitated by definitions maintaining that an abstract ideal of the Good Society is a central element of any ideology (e.g. Heywood 2002, 43; Seliger 1976). Adopting these definitions it can then easily be said that conservatism evades the label ideology for the simple reason that different societies have different things to conserve. Granting that the meaning of the verb "to conserve" is relevant for the concept of conservatism does not of course compel the scholar to surrender to the conservative denial of ideology. It rather serves as an invitation to rethink definitions of ideology in order to include conservatism. Conceding that conservatism abjures abstract ideals of the Good Society is something quite different from purporting that conservatism is not conducive to analytic treatment after all.

Huntington's (1957) distinction between ideational and situational ideologies represents such an attempt to grasp conservatism as an ideology. He confirms that conservatism lacks "what might be termed a substantive ideal" (457). While ideational ideologies such as liberalism and socialism aspire to the realization of universal normative ideals of social order, Huntington suggests, conservatism is a situational ideology that is not defined by a specific end or ideal it promotes, but rather by the stance it takes to the social order that happens to be in place. In contrast to a radical stance that recommends changing the contingently established social order, whatever it 
is, the conservative stance recommends defending the status quo, whatever it is, and oppose change, whatever it aims for:

[Conservatism] justif[ies] any established order, no matter where or when it exists, against any fundamental challenge to its nature or being, no matter from what quarter [...] Conservatism is not just the absence of change. It is the articulate, systematic, theoretical resistance to change. $(455,461)$

Huntington remarks that, following the conservative stance consistently, Burke recommended Whig policies in England, the caste system in India, democracy in America, for France autocratism before the French Revolution had succeeded, and republicanism afterwards (463).

A compelling argument in favour of the situational understanding of conservatism is that it facilitates the search for an underlying rationale guiding conservatives in different historical and cultural contexts instead of either associating, rather arbitrarily, conservatism with one such context (e.g. Mannheim 1953) or promulgating, rather hastily, its inconsistency (e.g. Alexander 2013). On the one hand, it is not clear why conservatism - were it the "function of one particular historical and sociological situation“, as Mannheim (1953, 98-9) claimed - should be identified with the feudalaristocratic reaction to the French Revolution rather than some earlier, later, or nonEuropean political groups that wished to see the existing order defended and change resisted. ${ }^{7}$ Even if many of these political groups did not call themselves conservatives or employ the word "conservatism", it is difficult to deny that they had the concept of conservatism, precisely because they wished to see the existing order defended and change resisted. On the other hand, the heterogeneous policies advocated by "conservatives" at different times can serve as an evidence for the intrinsically contradictory nature of conservatism only if the policies produced by an ideology were necessarily to be considered synchronically and independent of concrete contexts. If, however, the idea is taken seriously that an ideology may be characterized by an attitude towards the contingently established order or potential changes rather than by

7 Mannheim's attempt to avoid this problem by establishing the notion of traditionalism as a residual category is unsatisfying for two reasons. Firstly, Mannheim's suggestion that human beings have a general weakness for the traditional is questionable (Vierhaus 1997, 532; Oakeshott 1991b, 425). Secondly, we will see in Section 3 that the aspiration to continue traditions is only one way among others in which the imperative of conservation can be conceptualized. 
a universal and timeless normative ideal of social order, the policies implied by an ideology need to be compared diachronically and in relation to their respective contexts of origin. With the situational understanding of ideology in mind, we should therefore rather become suspicious when self-proclaimed conservatives pursue the same agenda in different situations, when they equally venerate, for instance, a hierarchically structured society or laissez-faire capitalism.

The distinction between ideational and situational ideologies allows us to discard two other popular accusations against conservative ideology. Conservatism is occasionally said to fail to constitute a viable ideological alternative because it is not merely opposed to rival ideologies, but actually defines itself by negating all currently relevant ideologies, thus constituting a parasitic negative substrate (Alexander 2013, 603-4). Yet if conservatism is approached in situational terms, the point of reference is the existing order or change, not other ideologies. Moreover, conservatism cannot possibly antagonize all other ideologies. While it might be true that conservatism de facto stands in opposition to any ideology that happens to challenge a currently existing order, it must at least find an ally in the ideology of the prevailing hegemony. Huntington (1957, 473) concludes accordingly that liberals in America, if they wish to repel the menace of socialism, must become conservative. The question is, however, whether true conservatives are actually always the ideological adherents of the prevailing hegemony or whether, as I will argue later on, they are only empirically indistinguishable from them.

Relatedly, conservatism has frequently been attributed a sociological dimension and characterized, put simply, as a cloak for upper-class self-interest (Honderich 1990, 238; Müller 2006, 361). This view builds upon a reductionist account of individual or class interest, if only because members of the social and economic elite who adhere to, say, liberalism or socialism would suffer from false consciousness. Equally questionable is the implicit assumption that the maintenance of prevailing power relations is generally in the "rational" self-interest of the better off. At least for modern democracies as we know them, reforms that would help make the wealthy even wealthier and the mighty even mightier can easily be envisioned. ${ }^{8}$

Huntington's characterization of conservatism as a situational ideology is a useful tool to account for and make sense of its peculiarity, and will inform my basic

8 For similar criticisms of the "sociological" characterization of conservatism see Brennan and Hamlin (2014, 6-7), Hamlin $(2013,4)$, and Huntington $(1957,457)$. 
understanding of plausible conceptions of conservatism in the following. Yet this tool does not do the political theorist's job by itself, and Huntington's analysis of conservatism as a situational ideology remains as fuzzy as his provocative rhetoric is misleading. As regards the latter, it is important to note that Huntington does not define conservatism as a categorical rejection of change - although he occasionally seems to be happy to convey this impression - and mentions at one point that the conservative may well "acquiesce in change on secondary issues" (Huntington 1957, 455). Conservatism, just as other ideologies, is best understood as something that may come in different degrees. What is important from the perspective of a minimalist approach is the characteristic feature of an ideology. For conservatism, on Huntington's account, this is (merely) an inclination that other ideologies do not have, namely the inclination to defend the status quo, whatever it is, and oppose change, whatever it aims for. While the situational understanding requires that this inclination be systematically at work, it may well become overridden by other considerations in any particular case.

Huntington's account remains fuzzy because it is not entirely clear which of the two categories - the status quo or change - ultimately takes precedence over the other. At various points he affirms that the systematic resistance to change is the guiding thought of conservatism and the preference for the status quo only a practical implication thereof. However, occasionally he seems to think that the reverse is true, for instance, when he says that "no one can espouse the conservative ideology ... unless he is fundamentally happy with the established order and committed to its defense against any serious challenge" (Huntington 1957, 455). Also, the normative preference for the status quo appears to be the logical cause for the disinclination to undertake change when he states that change on secondary issues might be necessary in order to preserve the fundamental elements of society (455). Not only, then, is the continuation of the status quo the purpose of action, also what kinds of change affect secondary issues can only be determined in relation to the status quo.

In order to clarify the role that (the opposition to) change and (the defence of) the status quo may plausibly play in a conception of conservatism, and whether more than one such conception is possible, we need to reflect about the justifying philosophical rationales of conservatism in greater detail. 
Oakeshott's (1991b) essay On Being Conservative exhibits striking similarities to Huntington's Conservatism as an Ideology, not least because the opposition to change and the preference for the status quo are also singled out as the characteristic features of conservatism. In slight divergence from Huntington, Oakeshott suggests that neither of the two features is logically prior to the other, but rather that they are two sides of the same coin that together make up the conservative disposition:

The disposition to be conservative is, then, warm and positive in respect of enjoyment and correspondingly cool and critical in respect of change and innovation: these two inclinations support and elucidate one another. (411)

Given that Oakeshott contents himself with providing a phenomenological description of the conservative disposition "as it appears in contemporary character" (407), he does not attempt to scrutinize whether the two inclinations are grounded in rationales that both constitute logically sufficient conditions for being conservative. Brennan and Hamlin $(2004 ; 2013 ; 2014)$ have recently undertaken this task. Their analysis therefore directly assists the identification of independent plausible conceptions of conservatism and further inquiry into the question of what it may mean to be a true conservative.

\section{$\underline{\text { 3.1 Adjectival Conservatism }}$}

Brennan and Hamlin argue that the inclination to oppose change is best explained in terms of a specific posture relative towards values. The keyword, here, is risk aversion in the face of uncertainty, and it may relate to policy outcomes and policy goals. Brennan and Hamlin call this adjectival conservatism. Even if an adjectival conservative shares the same goal as others, she will adopt a more defensive tactic in the pursuit of this goal because she places a greater emphasis on the limits and fallibility of human knowledge. Classical arguments brought forward for this defensive tactic, as Hirschman (1991) has noted, hold that the failure to fully anticipate the effects of reform threaten to undermine or pervert its utility. Accounts of a precautionary or change principle are more recent argumentative strategies (e.g. Gardiner 2006; 0’Hara 2011, esp. 88-9). The common topos of these arguments is often that the test of time is an equally important, if not superior, guide to good governance as compared with scientific risk calculation. 
Brennan and Hamlin (2004) themselves piece together another line of justification from economic theory that is predicated upon the diminishing marginal utility of preferences plus the assumption of uncertainty. If a reform is assumed to be equally likely to increase or decrease the desired value by the same amount, it is rational to oppose the reform because "the potential welfare losses from moving in the 'wrong' direction systematically exceed the potential gains from moving in the 'right' direction" (685).

Other uncertainty-related considerations may provide further reasons for a defensive tactic when pursuing desired goals. Slippery slope arguments recommend the exercise of restraint with regard to policy reform because a change in policy needs not be accompanied by a change in the inhibition threshold for making future changes in that policy field. If decision makers at later points are equally inclined to take a risk as decision makers in the present situation, they must be expected to enact a change of the same quality as the initial policy, and therefore go well beyond what was initially desired (e.g. Cohen 2012, 150-1; Walton 1992). Certain institutional settings might also decrease the inhibition threshold of decision makers. Arguably, for instance, competitive democracy creates an incentive structure that encourages actionism because opposition parties must promise and rationalize the desirability of policy change in order to justify their claim to power, regardless of whether they actually desire policy change or not (see also Brennan and Hamlin 2004, 683-4).

The aversion to taking on the risk of conducting reforms is intensified if policy goals are themselves affected by uncertainty; if, in other words, it is not clear whether the desired goals are actually desirable. Oakeshott's (1996, esp. 31) critique of perfectionism in politics (the "politics of faith") constitutes a sophisticated articulation of this rationale for adjectival conservatism. Without calling the existence of universal and timeless ideals into question one may dispute that these ideals are epistemologically accessible. The pursuit of policies aiming at the promotion of any such ideal is therefore not necessarily wrong, yet pretentious, and to the extent that the pretension of having identified the best social order is considered reason enough to enforce its realization, also reckless. Note that a commitment to adjectival conservatism based on the uncertainty of goals is less demanding than philosophical anti-foundationalism, given that it issues a caveat not against political philosophies that construct normative ideals, but only against their passionate pursuit in practice. 


\section{$\underline{3.2 \text { Nominal Conservatism }}$}

Justifications of the inclination to stick to the status quo, Brennan and Hamlin point out, are based on a different kind of rationale, viz. one that is based on the belief in a specific kind of value. Nominal conservatism, as they call it, assesses alternative states of the world not exclusively by the values that reside in them, but attributes an additional "existence value" to that state of the world that happens to be the status quo. Again, the purpose is a description rather than a justification of this rationale. However, to give an idea of the range of arguments that might support nominal conservatism (see Brennan and Hamlin 2013; Cohen 2012; MacIntyre 2011, esp. ch. 15; Matthes 2013), it can be said that the specific kind of value attributed to existing things might be seen to reside in the existence of the thing itself on account of its particularity, irreplaceability (in contrast to its commensurability), or historicity (i.e. time-honoured nature). Alternatively, existing things might be believed to have an existence value for those who encounter them because they are co-constitutive of personal identities.

Probably the argument most commonly put forward in the history of conservative thought, though, is that the existing order constitutes a tradendum over which the recipients have no sole discretionary power, or that the act of passing on a tradition imposes a normative obligation on its inheritors (Pieper 1970; Scruton 2001, 31-7; cf. Dittmann 2004, esp. 126-8). Burke's (2009, 95-6) remarks characterizing society as a partnership among generations and the duty of political stewardship are well-known and oft-cited, even though rather few attempts have been made to systematically develop the idea. Comparatively uncontroversial is the idea that the unquestioned existence of a large majority of institutions (and traditional knowledge) is valuable because it allows individuals to concentrate their energies on a limited number of projects, including the project of scrutinizing particular institutional alternatives (see esp. Dittmann 2004, 355-74). "Progress", William James is said to have remarked in this sense, "is a terrible thing in so far as it breaks up [...] the habits of thrift, of skill, of industry as well as the personal hopes and ambitions, and life-programs" (Park 1984, 108).

The attribution of existence value to the status quo is clearly distinct from doubts about policy outcomes and ends. The former amounts to an inclination to stick to the status quo because it is in some sense considered intrinsically valuable; the continuation of the established order is the goal. In the latter, scepticist considerations feed a disinclination to undertake change because change is considered to be fraught with 
risks; the goal is to manage change and make politics a safer affair. Due to the distinctive nature of the two kinds of rationales, Brennan and Hamlin conclude that the scepticist adjectival conservatism and the substantive nominal version each constitute a sufficient basis for true conservatism. In addition, they note (without discussing it at length) that there is a third conception of conservatism - practical conservatism - and that persons committed to any of them in any combination may legitimately call themselves truly conservative:

These three forms of conservatism ... may operate in any combination, so that ... we may identify a total of seven forms of conservative disposition each characterised by a particular combination. [(i) an adjectival conservative; (ii) a nominal conservative; (iii) a practical conservative; (iv) an adjectival and nominal conservative; (v) an adjectival and practical conservative; (vi) a practical and nominal conservative; (vii) an adjectival, practical, and nominal conservative.] But, in our view, each of these seven has a real claim to the title conservative. (Brennan and Hamlin 2014, 9)

However, there is good reason to believe that at least the conception of practical conservatism cannot draw on a distinct kind of justifying rationale, and therefore can be absorbed by adjectival and nominal conservatism.

\section{$\underline{3.3 \text { Practical Conservatism? }}$}

In Brennan and Hamlin's view, a person that lacks a commitment to conservatism in the adjectival and nominal sense is still a proper conservative if she holds certain unusual empirical beliefs about the transactions costs of political reforms or, respectively, the real costs of departures from the status quo. The example they provide for such an unusual empirical belief is that "the status quo might be seen as a social equilibrium involving a variety of conventions and that it will typically be costly to shift from one convention equilibrium to another" (Brennan and Hamlin 2013, 2; cf. also 2014, 9).

The idea that the intrinsic desirability of political reform is systematically diminished by hidden costs is commonplace in conservative thought. Order is commonly characterized as organic: as a complex and fragile arrangement of institutions that are functionally interdependent and mutually sustaining. Alternatively, existing institutions are said to have functions in addition to their avowed purposes that are unrecognized or 
seen only in hindsight (cf. Muller 1997, 15-7). If so, already the replacement of a minor institution must jeopardize the whole equilibrium. Additional costs would have to be attributed to political reform because a new equilibrium would have to be attained or, at least, because latent functions would have to be compensated. Good governance would be, as Oakeshott $(1996,32,36)$ says, "order guardianship" because order is "a great and difficult achievement never beyond the reach of decay and dissolution". Regardless of whether a general belief in the latent functions and functional interdependence of existing institutions is reasonable or not, it is - pace Brennan and Hamlin - largely related to the issue of uncertainty about policy outcomes and ends that is characteristic for adjectival conservatism.

It is already theoretically uncertain whether the latent functions of an existing institution are desirable or undesirable, even though the test of time might be considered a point in their favour. More importantly, however, the person who believes in the general existence of latent functions must assume that an institutional alternative, once put into place, also has latent functions in addition to its avowed purpose that cannot fully be foreseen. The latent functions of the institutional alternative might even be more valuable than those of the existing institution. In other words, the belief in the existence of additional transactions costs for political reforms arising from the latent functions of existing institutions (or the disruption of the equilibrium) necessarily implies the possibility of lower maintenance costs of institutional alternatives (or a new equilibrium). Of course, maintenance costs may also be higher. But the expectation that political reforms, due to the higher maintenance costs of institutional alternatives as compared with existing institutions, will incur transactions costs in addition to the obvious replacement costs is less an empirical belief than an expression of risk aversion or "prudential diffidence" (Oakeshott 1996, 31) in the face of uncertainty.

If the belief about the real costs of departure from the status quo that Brennan and Hamlin consider specific for the practical conservative is not entirely attributable to adjectival conservatism, then it is only so because one might consider the status quo to be valuable as such, which is the defining feature of the nominal conservative. Nominal conservatives who, more than others, attribute particular or historical value to existing institutions in addition to their instrumental value, who feel that existing institutions are co-constitutive of their identity and consider a change of their identity to be costly, or who consider institutional continuity to be more important for the realization of 
individual hopes and ambitions, must estimate higher real transactions costs for political reform than nominal non-conservatives.

Hence, the idea of a distinct "practical" conservatism does not withstand scrutiny, and the seven possible options of true conservatism, as sketched by Brennan and Hamlin, narrow down to three: an adjectival conservative, a nominal conservative, and a person that is conservative in both the adjectival and the nominal sense.

\section{ON BEING TRULY CONSERVATIVE}

Or can the options be further reduced? Is there any reason to believe that claims to ideological authenticity in the case of conservatism must necessarily result either from a commitment to adjectival conservatism, nominal conservatism, or from a commitment to both? So far I have reconstructed conservatism as a situational ideology and argued that conceptions can be based either in a risk-averse attitude that is predicated upon uncertainty (adjectival conservatism) or in a belief in some kind of existence value (nominal conservatism). In the last two sections I will argue that - while adjectival and nominal conservatism are both plausible conceptions of conservatism - only the latter constitutes a sufficient basis for claims to being truly conservative. ${ }^{9}$ To make this point, it is revelatory to exploit a distinction that is latent in Oakeshott's (1991b) essay On Being Conservative, namely that between having conservative convictions on the one hand and engaging in conservative conduct on the other. After making this distinction manifest and spelling out its implications, I will walk the reader through a series of hypothetical examples to show that adjectival conservatism must be dismissed as an insufficient basis for being truly conservative.

Despite the essay's title, Oakeshott's On Being Conservative is not a general apology of the conservative disposition. Instead, it is a very specific justification of conservative conduct in politics. The distinction between the conservative disposition (or conservative convictions) and conservative conduct is easily overlooked in the essay because Oakeshott does not explicitly highlight its significance for his argument. Also, the remarkable literary quality of the beginning of the essay abets the monopolization of a reader's attention on his description of the conservative disposition, which is

9 For the sake of simplicity I will therefore not make explicit reference to the case of a person who is conservative in both the adjectival and the nominal sense. 
contained in those pages. While Oakeshott in the middle of the essay actually comes out in favour of the appropriateness of the conservative disposition in some realms of an individual's life (and its inappropriateness in others), the essay then takes a twist when Oakeshott turns to the realm of political life, as he goes on to discuss not the appropriateness of the conservative disposition, but the appropriateness of conservative conduct. Conservative conduct, Oakeshott tells us, is called for in politics because it injects "an ingredient of moderation" into the "self-government of men of passionate belief and enterprise" (432-3). Are people generally of passionate belief and enterprise? Oakeshott does not think so. He only suggests that there is sufficient reason to believe that people are of such a character "in our own contemporary circumstances" (421). Hence, his recommendation for conservative conduct hinges on specific contingent conditions; it "does not entail either that we should hold these beliefs [the convictions of a person of conservative disposition] to be true or even that we should suppose them to be true" (422). The reluctance to change the status quo, Oakeshott teaches us in short, may - but need not - stem from the inclination to prefer the status quo because it is the status quo or oppose change because it is change; it may also be motivated by contingent circumstances. Given that Oakeshott grounds his case for conservative conduct in external factors, not inner convictions, and given that convictions trump behaviour when it comes to determining the identity of a person, the punch line of his essay becomes clear: in the present context it is reasonable to act like a conservative without actually being one.

Whether Oakeshott's observation of his British contemporaries' character pertains or not is of no concern for the present theoretical discussion. Two insights, however, are important. Firstly, contingent circumstances may lead one to act at variance with one's own ideological self-understanding. To illustrate this point, consider the example of a fur trader. One day, this fur trader is observed to release a coyote from a trap. It would mean leaping to conclusions were one to say that the fur trader is actually, or has become, an animal liberationist; she might simply hunt raccoons. Conversely, a person that does not remove a coyote from a trap might still be a real animal liberationist; external circumstances - for instance that the coyote has rabies - may have overridden her convictions. Analogously, a person is truly conservative if and only if her thinking about social affairs is generally influenced by convictions that are, in a distinctive sense, conservative; she is not if mere circumstance makes her act as a principled conservative would be expected to act under normal conditions. Secondly, the contingent 
circumstances that may lead one to act like a conservative can be of a different kind. Most obviously, the existing social order is such a contingent circumstance. In a perfectly liberal society, a true liberal behaves in politics just like a (nominal or adjectival) conservative; she will do very little to promote a systems change. Perhaps true liberals are well advised to rely primarily on genuinely conservative arguments in order to defend even a fairly liberal order against challenges from non-liberal ideational ideologies until consolidation is achieved, as Huntington wanted to make his fellow Americans believe at the beginning of the Cold War. ${ }^{10}$ But the conservative behaviour of this true liberal does not make her faithful to conservatism; and while the strategic recourse to conservative rhetoric might tarnish her moral integrity, it does not undermine her ideological authenticity. By the same token a true conservative is not identical with a true liberal simply because the prevailing order happens to be liberal, and more generally speaking, she is not a proponent of the ideology of the prevailing hegemony. They just find themselves in their political conduct to be brothers in arms.

Conservative conduct is a deceptive indicator for the assessment of a person's ideological affiliation. However, comparing the (hypothetical) behaviour of a person in two situations, with certain contingent circumstances present in one and absent in the other, helps sharpen our analytical understanding. For instance, a person who had not done much to promote a systems change when a liberal order was in place, and is not more active once the liberal order has been replaced with a socialist one, cannot be a liberal and nothing else. She must be a nominal conservative, who is inclined to defend the status quo, whatever it is; or, at least in addition to being a liberal, she must also be a rather extreme adjectival conservative and refrain from dissident behaviour on risk and uncertainty-related grounds.

As this reversal test implies, an adjectival conservative cannot be distinguished from a nominal conservative on the basis of conduct, if types of social order are isolated as the external factor that may make a person act at variance with her general ideological convictions. However, another kind of contingent circumstances accomplishes the purpose. Uncertainty about policy outcomes and goals is, to a very large extent, on any

10 The repetition of liberal ideology, Huntington claimed, did not help to repel the threat of socialism posed by the Soviet Union. Due to its ideational nature, liberal ideology is bound to encounter socialism at the same level of last questions and final answers. However, conservatism, because of its situational nature, manages to immunize the established liberal society against any challenge from ideational ideologies. Therefore, Huntington $(1957,458,470-3)$ concludes, “American liberals have no recourse but to turn to conservatism... [and] accept the values of conservatism for the duration of the threat." 
reasonable account just such a kind of external contingent circumstances. Constructing a respective reversal test lends credence to the view that adjectival conservatism is an insufficient basis for claims to true conservatism: a person who had not been inclined to promote innovation in a situation characterized by conditions of uncertainty related to policy goals or outcomes, and is equally disinclined to promote innovation once those conditions have become much more favourable, cannot be an adjectival conservative only. She must be a nominal conservative too. With this case in mind, adjectival conservatism turns out to be just a formalized, generalized, and abstract theoretical articulation of contingent circumstances that are likely to make proponents of other ideational ideologies behave in politics as if they were true conservatives.

\section{THE SCEPTICIST OBJECTION}

Whoever follows the line of argument up to this point might object that adjectival conservatism is nevertheless a sufficient basis for being truly conservative. One could argue that risk and uncertainty qualify not simply as possible contingent circumstances in the view of the adjectival conservative, but are permanent features of the human condition. The absence, not the presence, of risk and uncertainty was occasionally an external factor altering the adjectival conservative's behaviour. Adjectival conservatism, one could say, is a scepticist ideology, with limited rationality and capacities for information processing and planning being its central creed. However, the insistence that adjectival is a sufficient basis for being truly conservative would have to refute three additional arguments to which nominal conservatism is immune: an appeal to intuition, the problem of conceptual overstretch, and the possibility of a faulty generalization that is retrieved via the deceptive method of tracking a person's character via her behaviour, which takes the form of an invalid syllogism.

Firstly, imagine that a registered member of the Christian Democratic Union of Germany runs for a party office and tries to garner support by claiming to be truly conservative. The general idea that the status quo is to be valued because it is the status quo does not appeal to her. Neither does she cherish the liberal democratic order that is in place in Germany today for ideological reasons. In fact she is decidedly critical of it and dreams of communism. Yet as she believes that a coup d'état without leaders of Herculean rationality is unlikely to succeed in the present context, and that an 
imperfectly planned sequence of reforms might well delay rather than promote the desired systems change, she refrains from proactively working towards the realization of communism. Calling this risk-averse communist a true conservative blatantly contradicts common sense. Her inclination to oppose radical change is wholly conditional, based on an assessment of contingent circumstances. She acts like a conservative not out of principle but out of strategic calculus, and is prepared to change her political behaviour as soon as the circumstances change. A follow-up example makes the assault on intuition by the scepticist objection even clearer. At one point, the riskaverse communist opposes a reform meant to promote central ownership and control of the means of production because she sees the risk that the reform will perversely inhibit the realization of communism in the long run, if undertaken in the present context. However, the parliament passes the reform bill and it becomes a thorough success. She might still insist that her reservations were justified in the initial decision situation and dismiss subsequent reform bills meant to promote the communist cause for the same risk-related reasons. Yet she would have to admit that in regard to the first reform bill her conservative conduct was misplaced, precisely because she was wrong in her assessment of circumstances and risks that made her act as if she had conservative convictions. As it happened, the behaviour of the risk-averse communist was conservative in the decision situation, not the person herself.

Secondly, the category of being truly conservative would suffer from conceptual overstretch if adjectival conservatism was accepted as a sufficient condition. Let alone the risk-averse communist in the hypothetical example, most members of all "moderate" party wings - such as for instance the "Realos" of the German Green Party ${ }^{11}$ - could be considered truly conservative on this basis. It also only makes polemical sense, to give another real-world example, to say that John Rawls was a true conservative because he was more reluctant to make the difference principle operational than other proponents of property-owning democracy (e.g. Williamson 2012). While considering the difference principle an essential part of his theory of justice (and for that matter, the realization of a just order, namely a property-owning democracy), he recommended that it be stated only in a non-enforceable preamble of the constitution as an aspirational principle

11 In the rough-and-tumble play of ordinary political discourse the Realos of the German Green Party are regularly taunted as being "blacks" (i.e. conservatives) who are equipped with "green" party membership cards (e.g. Deininger 2013). On the basis of the discussion provided in this article it seems more appropriate to say that they are green by conviction and conservative by circumstance, or green at heart and conservative at head. 
because it is not possible "to settle with exactness" whether the principle is met (Rawls 2001, 162).

Thirdly, note that the characterization of adjectival conservatism as a viable option for being truly conservative might be exclusively principled upon the hasty conclusion that observable conservative conduct is a sign of conservative convictions. Does it not seem compelling to assume that a person who is equally disinclined to promote innovation in two different kinds of social order actually must be motivated by an esteem for the status quo, whatever it is? Is the polemical characterization of the "Realos" of the German Green Party as true conservatives - because they are less idealistic about the prospects of turning Germany overnight into a paradigmatically ecological, pacifist, vegetarian, multicultural, open border, poverty-free, nondiscriminatory, non-hierarchical and direct democracy than the Green "Fundis" - not just a small cognitive step further? Such polemics often work so effectively because they get mileage out of forensic rhetoric, which teaches that even attentive listeners have a hard time discerning valid from invalid syllogisms, if they deal with sufficiently abstract things. The equation of a person who is particularly strongly concerned about risks and uncertainty in regard to policy outcomes or goals with a true conservative would accordingly commit the fallacy of the undistributed middle, which is perhaps also occasionally committed when monarchists, libertarians, or xenophobic persons are identified as conservatives:

Fallacy of the undistributed middle ( $\mathrm{Z}$ is $\mathrm{B}$; $\mathrm{Y}$ is $\mathrm{B}$; therefore, $\mathrm{Y}$ is $\mathrm{Z}$.): E.g. Dogs are animals; cats are animals; therefore, cats are dogs.

Conservatives are right-wing; monarchists, libertarians, and xenophobic persons are right-wing; therefore, monarchists, libertarians, and xenophobic persons are conservatives.

Conservatives are in cases of doubt reluctant to change the status quo; risk-averse persons („adjectival conservatives“) are in cases of doubt reluctant to change the status quo; therefore, risk-averse persons are conservatives.

\section{CONCLUSION}


It certainly makes good analytic sense to describe the systematic reluctance to undertake change motivated by risk-aversion as a kind of conservatism, and it definitely makes better sense than describing as such the adherence to the ideology of the prevailing hegemony in one or another historical situation. Yet adjectival conservatism is still derived indirectly from the similarities in conduct that will usually obtain from a principled attribution of value to the status quo because it is the status quo. To the extent that the wording "adjectival" conservatism expresses this second-rate quality (as alluding to the syntactic role of adjectives to give additional secondary information about a primary noun), it is a well-chosen term. It would serve to express that an adjectival conservative whose political conduct is motivated by a sensibility to risk and uncertainty related to policy outcomes is only accidentally, but not essentially, a conservative. Being conservative, even truly conservative, may of course still come in different degrees and intensities. Risk and uncertainty as well as other contingent circumstances may well keep a faithful nominal conservative from opposing change in some situations (e.g. time-honoured institutions may decay or be in danger of decaying, traditions may become meaningless, etc.). At any rate, however, only a nominal conservative can legitimately lay claim to be truly conservative. Being truly conservative means to aim for the conservation of established institutions out of conviction and not happenstance; it means to have a presumption in favour of the given rather than a presumption in disfavour of the untried; to attach a value to the status quo because it is the status quo rather than disvalue change because it is change; and to act on an imperative of preservation because the desirability of continuity is supposed, not because the utility of innovation is doubted.

Despite the rejection of adjectival conservatism as a solid basis for claims to true conservatism, there is still considerable room for different versions of true conservatism. On the one hand, the commitment to the status quo, to which true conservatives attach a value because it is the status quo, can be justified in more than one way, as indicated above (see 3.2). On the other hand, the status quo is a particularly vague concept, leaving much room for debate as to what aspects of the status quo (e.g. embodied values, procedures, institutional structures, etc.) are the relevant aspects (cf. Faith 2004). Apart from theoretically unresolvable ambiguities, it is of course immensely difficult to settle disputes about the ideological authenticity of self-proclaimed conservatives in practice. Given that political behaviour is an unreliable guide for 
assessing true conservatism for the above-mentioned reasons, the external observer can only focus on self-proclaimed conservatives' explanations of claims in disputes over authenticity and justifications for their conduct in politics. The scholar is thus vulnerable to the rhetoric of disputants in contested disputes, and what is more, a variety of methods of interpretation that will usually arrive at different conclusions (and therefore are themselves subject to an on-going controversy) can be applied to identify the authorial intention behind the rivalling claims.

Nevertheless, it is at least possible to thin out the field of equally plausible claims because in many cases it is comparatively uncontroversial that the particular justifications provided by self-proclaimed conservatives in disputes over ideological authenticity are ill-suited to substantiate their claims to being truly conservative. To illustrate the assistance that this theoretical discussion may lend to evaluating such claims, consider a selection of recent statements made by Cameron concerning his ideological affiliation:

[M] any of you think I'm not really a Conservative at all... [but] I am Conservative because of the values that I have believed in all my life: family, responsibility and opportunity. I am a Conservative because I believe that those values lead inexorably to a political agenda whose central mission is to give people more power and control over their lives... Freedom is our mission, as it always has been... I am a modern compassionate Conservative. (Cameron 2007)

I've always described myself as a Liberal Conservative. I'm Liberal because I believe in freedom and human rights, but Conservative - I'm sceptical of great schemes to remake the world. (Cameron quoted from Shipman 2010)

No trace can be found in either quotation of a belief in the inherent value of the status quo. Instead, Cameron assures his audience of his steady personal commitment to values that allegedly result in one and the same political agenda in every context, which suggests that a non-conservative ideational ideology is at work. In the second quotation, his ideological positioning is characterized by reference to adjectival conservatism and liberalism. Cameron's statements would thus serve to substantiate not a claim to being a true conservative or true liberal conservative, but rather to being an adjectivalconservative liberal. However, given that elsewhere Cameron (2011) stressed his 
readiness to undertake institutional experiments in spite of risks, the statements on his ideological positioning suggest that he is not even firmly committed to adjectival conservatism; that he, without being truly conservative, is not even inclined to act systematically in politics as if he were a true conservative. Whether this finding - if the selection of statements is representative at all - speaks against rather than for Cameron is another question. Yet sympathizers of conservatism would be justified in denying Cameron the title of true conservative to which he aspires in order to appease some intra-party criticism of his political course.

\section{ACKNOWLEDGEMENTS}

I am grateful to Vanessa Rampton, the two anonymous reviewers, and especially Sebastian Muders for their help to improve the clarity of the argument.

\section{REFERENCES}

Alexander, James. 2013. "The Contradictions of Conservatism", Government and Opposition 48/4, 594-615.

Beckstein, Martin. 2014. "Traditions and True Successors. A Few Pragmatic Considerations". Social Epistemology Review and Reply Collective 3(3), 30-36.

Brennan, Geoffrey and Alan Hamlin. 2013. "Conservative Value.” MANCEPT working paper 7(13), 1-22. Online:

www.socialsciences.manchester.ac.uk/subjects/politics/our-research/researchclusters/manchester-centre-for-political-theory/working-papers/.

Brennan, Geoffrey and Alan Hamlin. 2014. "Comprehending Conservatism: Frameworks and Analysis." Journal of Political Ideologies 19/2, 1-13.

Brennan, Geoffrey, and Alan Hamlin. 2004. "Analytic Conservatism." British Journal of Political Science 34(4): 675-691.

Buchanan, James M. 2005. "Why I, Too, Am Not a Conservative", Chap. 1 in Why I, Too, Am Not a Conservative: The Normative Vision of Classical Liberalism, 1-10. Cheltenham: Edward Elgar.

Burke, Edmund. 2009. Reflections on the Revolution in France. Oxford; New York: Oxford University Press.

Cameron, David. 2007. "What Makes Me Conservative”. Daily Telegraph, 8 September 2007. Online: www.telegraph.co.uk (14 February 2014).

Cameron, David. 2011. "Speech on the Big Society". Milton Keynes, 23 May 2011. Transcript available online at www.newstatesman.com/ (14 February 2014).

Cohen, G. A. 2012. "Rescuing Conservatism: A Defense of Existing Value". In Finding Oneself in the Other, 143-174. Princeton, N.J: Princeton University Press.

Deininger, Roman. "Durch die Mitte zur Macht”, Süddeutsche Zeitung, 21 October 2012. Online: www.sueddeutsche.de (26 February 2014). 
Dewey, John. 2007. "The Reflex Arc Concept in Psychology", The Mead Project. Online: www.brocku.ca/MeadProject/Dewey/Dewey_1896.html (4 March 2014). Originally published in Psychological Review 3, (1896): 357-70.

Dittmann, Karsten. 2004. Tradition und Verfahren. Norderstedt: BoD.

Eccleshall, Robert. 2003. “Conservatism.” In Political Ideologies: An Introduction, edited by Robert Eccleshall, Alan Finlayson, Vincent Geoghegan, Michael Kenny, Meya Lloyd, Iain MacKenzie, and Rick Wilford. London: Routledge.

Faith, Roger L. 2004. "Can We Know the Status Quo?", Constitutional Political Economy $15,145-151$.

Freeden, Michael. 2008. Ideologies and Political Theory: A Conceptual Approach. Oxford: Oxford University Press.

Gardiner, Stephen M. 2006. "A Core Precautionary Principle”, The Journal of Political Philosophy 14(1), 33-60.

Hamlin, Alan. 2013 "Hayek, Buchanan and Conservatism". MANCEPT working paper 12(13), 1-18. Online: www.socialsciences.manchester.ac.uk/subjects/politics/ourresearch/research-clusters/manchester-centre-for-political-theory/working-papers/ (15 May 2014).

Hayek, F.A. 2011. "Why I Am Not a Conservative", Postscript in The Constitution of Liberty: The Definite Edition, 519-533. London: Routledge.

Heywood, Andrew. 2002. Politics. Basingstoke: Palgrave Macmillan.

Hirschman, Albert O. 1991. The Rhetoric of Reaction: Perversity, Futility, Jeopardy. Cambridge MA: Harvard University Press.

Honderich, Ted. 1990. Conservatism. London: Hamish Hamilton.

Huntington, Samuel P. 1957. "Conservatism as an Ideology." The American Political Science Review 51(2): 454-473.

Kirk, Russell. 1954. A Program for Conservatives. Chicago: Continuum.

MacIntyre, Alasdair. 2011. After Virtue. London: Bloomsbury.

Mannheim, Karl. 1953. "Conservative Thought". In Kecskemeti, Paul (ed.) Essays on Sociology and Social Psychology, 74-164. New York: Oxford University Press.

Matthes, Erich Hatala. 2013. "History, Value, and Irreplaceability". Ethics 123/1, 35-64.

Minogue, Kenneth. 1985. Alien Powers: The Pure Theory of Ideology. New York: St Martin's Press.

Müller, Jan-Werner. 2006. “Comprehending Conservatism: A New Framework for Analysis", Journal of Political Ideologies, 11(3), 359-65.

Muller, Jerry Z. 1997. "Introduction" in Conservatism: An Anthology of Social and Political Thought from David Hume to the Present, 3-31, Princeton: Princeton University Press.

O’Hara, Kieron. 2011. Conservatism. London: Reaktion Books.

O'Hear, Anthony. 1998. "Conservatism”, in Edward Craig (ed.) Routledge Encyclopedia of Philosophy, vol. 2, 609-615. London: Routledge.

Oakeshott, Michael. 1991a. "Rationalism in Politics." In Rationalism in Politics and Other Essays, 5-42. Indianapolis: Liberty Fund.

Oakeshott, Michael. 1991b. "On Being Conservative." In Rationalism in Politics and Other Essays, 407-437. Indianapolis: Liberty Fund.

Oakeshott, Michael. 1996. The Politics of Faith and the Politics of Scepticism. New Haven, Conn.: Yale University Press.

Payton, Jonathan. 2013. “Ruben's Account of Traditions and True Successors: Two Modificaions and an Extension", Social Epistemology Review and Reply Collective 2(11), 40-46.

Pieper, Josef. 1970. Überlieferung: Begriff und Anspruch. München: Kösel. 
Rawls, John. 2001. Justice as Fairness: A Restatement. Cambridge/MA: Cambridge University Press.

Robert E. Park. 1984. "Community Organization and Juvenile Delinquency", in The City edited by Robert E. Park und Ernest W. Burgess, 99-112. Chicago: University of Chicago Press.

Ruben, David-Hillel. 2013. "Traditions and True Successors." Social Epistemology 27 (1): $32-46$.

Scruton, Roger. 2001. The Meaning of Conservatism. Basingstoke: Palgrave Macmillan.

Seliger, Martin. 1976. Ideology and Politics. London: Allen \& Unwin.

Shipman, Tim. 2010. "Cameron Declares Himself a Liberal AND a Tory". Mail Online, 17 May 2010. Online: www.dailymail.co.uk/(14 February 2014).

Viereck, Peter. 2009. Conservatism Revisited: The Revolt Against Ideology. 3rd paperback. New Brunswick, N.J: Transaction Publishers.

Vierhaus, Rudolf. 1997. "Konservativ, Konservatismus”. In Gesellschaftliche Grundbegriffe: Historisches Lexikon zu politisch-sozialen Sprache in Deutschland, edited by Otto Brunner, Werner Conze and Reinhart Koselleck, 531-565, Stuttgart: KlettCotta.

Walton, Douglas N. 1992. Slippery Slope Arguments. Oxford: Clarendon Press.

White, Reginald J., ed. 1957. The Conservative Tradition. New York: New York University Press.

Williamson, Thad. 2012. "Realizing Property-Owning Democracy: A 20-Year Strategy to Create an Egalitarian Distribution of Assets in the United States" In Property-Owning Democracy: Rawls and Beyond, edited by Martin O'Neill and Thad Williamson, pp. 225248. Chichester: Wiley-Blackwell. 